\title{
A Power-electronics-based Modular Nanosecond Pulse Generation System for Plasma-assisted Ignition
}

\author{
Peng Gao* Non-member, Sean O'Byrne* Non-member \\ John E. Fletcher ${ }^{* a)}$ Non-member
}

(Manuscript received Aug. 11, 2014, revised Nov. 24, 2014)

\begin{abstract}
Plasma-assisted ignition technology has been proposed to boost the combustion efficiency of scramjets during highspeed flight. One technique utilizes high-voltage nanosecond-duration pulses, which can generate free radicals, thereby initiating ignition earlier in the combustion chamber and improving fuel efficiency. A high-voltage nanosecond pulse generator is an integral part of the system. In this study, a modular nanosecond pulse generation system, utilizing multiple high-speed high-voltage MOSFETs, is developed and tested. The modular system can generate width-adjustable pulses (from $20 \mathrm{~ns}$ to $50 \mathrm{~ns}$ ) with a fast rise time ( $<6 \mathrm{~ns})$, fast fall time $(<6 \mathrm{~ns})$, and variable amplitude using multiple switch cells. The system is also scalable in voltage and current. By employing the inductive voltage adder, the system is configured in two different ways: two switch cells coupled in parallel and two switch cells coupled in series. These configurations demonstrate scalability and the fundamental sizing constraints.
\end{abstract}

Keywords: nanosecond pulse generation, inductive voltage adder

\section{Introduction}

The supersonic combustion ramjet (scramjet) requires the fuel and air to mix rapidly with subsequent ignition. The time required to ignite the fuel/air mix has an important impact on the overall efficiency of the scramjet ${ }^{(1)}$, because the ignition delay time is of the same order of magnitude as the residence time in the combustor. Reducing the ignition delay time improves combustion efficiency, as more of the heat release chemistry, which produces thrust, occurs within the combustion chamber. Millisecond improvements in the time to ignite the fuel/air mix enhances the output power considerably because of the short-time the gas remains in the chamber before the hypersonic flow sweeps the gas out of the chamber ${ }^{(2)}$. Several methodologies have been proposed to reduce the ignition delay time; one is plasma-assisted hypersonic ignition, which generates reactive species (atomic oxygen, atomic hydrogen or hydroxyl radical) to the fuel during the combustion process $^{(3)(4)}$. These species have the effect of accelerating the reaction rate and thus reduce the ignition delay time. The plasma-assisted hypersonic ignition technology has the benefit of shortening the ignition delay time especially in high speed combustion.

It is also important to ensure that these radicals are produced without significantly heating the flow. The thrust produced by the pressure rise due to combustion is strongly related to the temperature difference induced in the flow by the combustion reactions. Thus, a method for generating radicals in a non-thermal plasma is highly desirable.

a) Correspondence to: John E. Fletcher. E-mail: john.fletcher@ unsw.edu.au

* University of New South Wales

High Street, Kensington, NSW, 2052
One such method is the repetitively pulsed nanosecondduration discharge. Other successful methods include aerodynamic stabilization ${ }^{(5)}$, electron-beam-controlled discharges ${ }^{(6)-(8)}$ and repetitively pulsed nanosecond-duration discharge $^{(9)(10)}$. From a practical point of view, external ionization by nanosecond-duration pulses offers key advantages compared with other methods because short duration pulse generators are easy to operate and maintain ${ }^{(3)}$.

The plasma is generated by high-voltage nanosecondduration pulses. The high voltage will form electrons with energies of $10-15 \mathrm{eV}$, elevating the probability of breaking down more molecules in either air or fuel ${ }^{(11)}$. In other words, more reactive chemicals are generated. The plasma-assisted hypersonic ignition technology therefore has the potential of reducing ignition delay, increasing peak pressure and raising the heat release ratio in comparison with conventional ignition technologies ${ }^{(12)}$.

There are several popular methods of generating a highvoltage pulse, Marx generator, inductive voltage adder, Blumlein line pulse forming network and magnetic pulse compression $^{(13)}$. The Inductive Voltage Adder (IVA) is the most suitable high voltage pulse generation topology in this application because of its minor pulse delay, variable pulse duration and peak amplitude. It is reported that an IVA based pulsed power generator could deliver a pulse of $4 \mathrm{MV} / 60 \mathrm{~ns}^{(14)}$. Another IVA based pulse generator employs a transformer and a variety of semiconductor devices to expand peak voltage of output pulse ${ }^{(15)}$. However, the property of scalability through modularization for both current and voltage rating has not been investigated. The proposed pulse generation system investigates this property and this differentiates it from other IVA-based pulse generation system.

This paper investigates a power-electronics-based 
technology for improvement to hypersonic ignition technology. The overall objective is to develop a high-voltage, modular nanosecond pulse generation system. It should be capable of delivering a nearly square-shaped voltage pulse with the following parameters, fast rise time $(<6 \mathrm{~ns})$, fast fall time $(<6 \mathrm{~ns})$, variable pulse duration ranging from $20 \mathrm{~ns}$ to $50 \mathrm{~ns}$ and modular architecture such that the system is scalable in voltage and current. In addition, this paper also focuses on examining the effect of series-and parallel-coupling of the scalable system.

\section{System Design}

2.1 Literature Review The energy can be stored chemically (battery), mechanically (flywheel), or electrically (capacitor). The stored energy is shaped by a pulse forming system and released rapidly to the load by activating switches. The switch is a critical component of any highvoltage and compact pulsed power system.

With the evolution of semiconductor technology, solid state devices have attracted more and more attention for pulse power applications due to their excellent properties such as fast turn-on and turn-off time, low maintenance and cost. This leads to the retirement of traditional switches (spark gaps) in some applications. The most widely used semiconductor switches include MOSFET, IGBT, Thyristors and Silicon carbide $(\mathrm{SiC})$.

The MOSFET can be easily switched on by charging the gate and switched off by discharging the gate with the MetalOxide-Semiconductor gate structure equivalent to a capacitance ${ }^{(16)}$. The advantage of fast operation speed qualifies the MOSFET as a candidate for $\mathrm{MHz}$ repetitive pulsed power system. Since turn-on resistance increases with the blocking voltage due to the increase in the path length of current through the semiconductor, the MOSFET has a practical voltage limitation of typically $1 \mathrm{kV}$ and tends to be employed with a lower supply voltages. The switching characteristics of the MOSFET are affected by the intrinsic capacitance, resistance, gate charge and the reverse recovery characteristics of the body diode.

The IGBT has a similar structure to a MOSFET but with a $\mathrm{P}+$ layer. Therefore, it operates in a similar way at turnon. The injection of holes into the drift region significantly increases the conductivity to current flow, which is the advantage of IGBTs over MOSFETs ${ }^{(17)}$. The maximum voltage and current ratings are around $8 \mathrm{kV}$ and $1000 \mathrm{~A}$, respectively but not simultaneously. The internal structure of the IGBT includes a bipolar-junction-transistor, which provides a nearly constant voltage drop. As a result, for high-voltage ratings, the on-state losses are relatively small compared to the MOSFET at higher blocking voltages. From this point of view, the IGBT is suitable for high supply voltages. The only problem, however, is that it exhibits a tail current. In comparison to MOSFETs, IGBTs have slower turn-on and turn-off speeds but higher power capability.

Silicon carbide ( $\mathrm{SiC}$ ) is the most promising devices to be commercialized in the near future. Compared to Si devices, $\mathrm{SiC}$ devices have superior performances resulting from advanced electrical and material properties of SiC. At the present time, SiC JFETs are the most mature device. They have outstanding performance in their high voltage blocking capability, low voltage drop in their on-state, less switching time and thermal resistance. This is very attractive for applications that demand high power density or high operating temperature. However, SiC JEFTs are normally on and only a negative voltage could switch the device off; therefore, conventional gate drivers are not suitable.

The thyristor, employing a highly-distributed gate structure, can be turned on via the gate terminal but can only be switched off when the device conducting current falls to zero; thus, the switching speed is inferior to that of MOSFET and IGBT. It offers the advantage of high voltage rating (around tens of $\mathrm{kV}$ ). The current rating is related to the size of the thyristor wafer. The gate turn-off thyristor (GTO) is an enhanced version of a thyristor, which can be forced off by diverting $20 \%$ typically of the collector current out of the gate. The advantage of high voltage and current ratings makes it suitable for low speed pulsed power ${ }^{(18)}$.

The superior operation speed of the MOSFET makes it the most suitable candidate for achieving the design criteria of this work, nanosecond switching speed. Although the power capability is inferior compared with other switches, a modular approach using MOSFET-based cells, that can be stacked, could provide a competitive technique.

2.2 Structure of the System The overall functional block diagram of the modular nanosecond pulse generation system employing inductive voltage adder is shown in Fig. 1. It utilizes several switch cells (in this case, 2) which are supplied by a common DC voltage supply, $V_{d c}$. Each switch cell includes a high-speed gate driver, a set of DC capacitors, a HV MOSFET switch and ancillary components. The gate driver receives the variable pulse-width logic signal from the controller unit so as to control rapidly the state of the MOSFET. Once the MOSFET turns on, a high-voltage output will be induced at the secondary windings, because of the rapid change of magnetic flux in the primary winding. Figure 2(a) shows the transformer arrangement used to series-couple output voltages from the two cells using two toroidal cores with a common secondary conductor. The cells can also be parallel coupled where each cell drives a primary wound around one toroidal core with one secondary turn, as shown in Fig. 2(b). In each case, a single primary and secondary turn is used to minimize leakage inductance (which rises to $N^{2}$ ). Leakage inductance is a primary limitation on achieving nanosecond rise times as it increases the $\mathrm{L} / \mathrm{R}$ time constant of the circuit. The transformer reset circuit is vital for demagnetizing (resetting) the transformer cores prior to the next pulse.

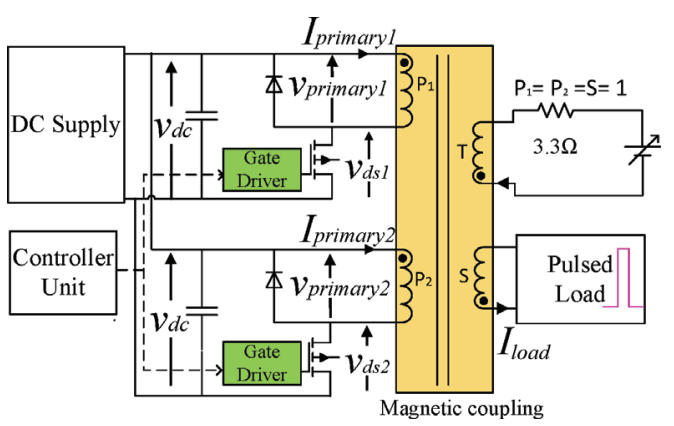

Fig. 1. Diagram of the porposed prototype design showing two switch cells series coupled and core reset circuit 


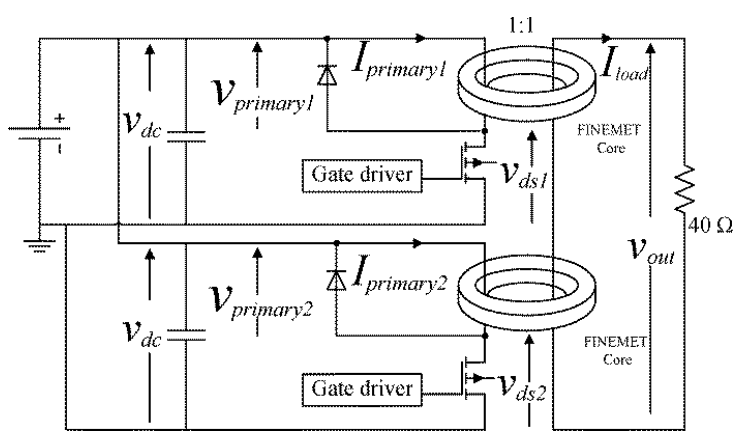

(a)

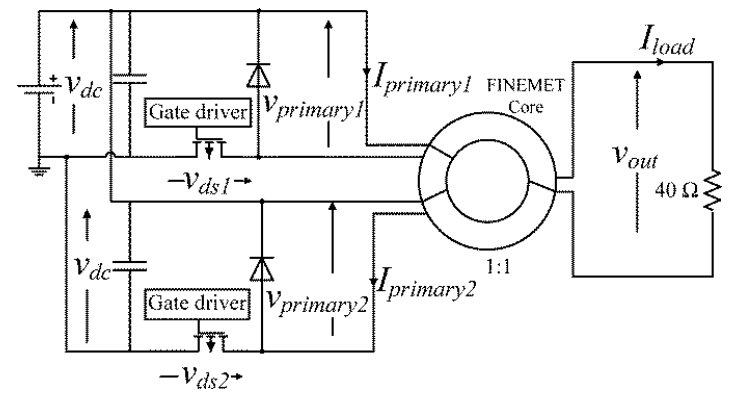

(b)

Fig. 2. The arrangement of two switch cells coupled in (a) series with two cores where each core has one primary turn driven by its own cell and a common secondary turn and (b) parallel with one core where each of the two cells drive their own single primary turn and the secondary has a single turn

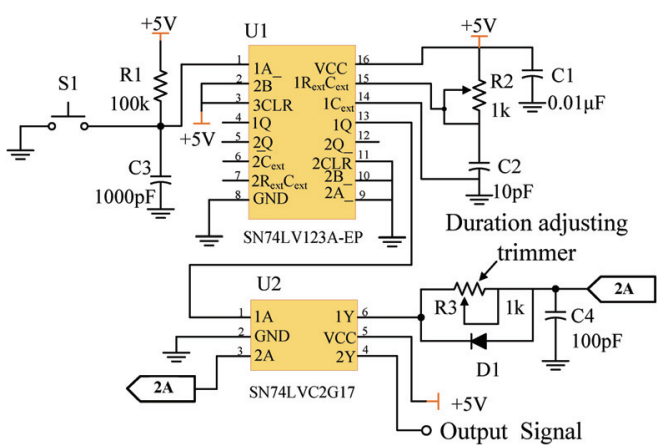

Fig. 3. The schematic diagram of the controller unit showing the pulse generation unit and pulse adjustment circuit

2.3 The Controller Unit The controller unit is designed to generate a debounced and adjustable-width signal. Figure 3 is a schematic diagram of the controller unit, which uses a dual retriggerable monostable multivibrator and a Schmitt input buffer. The retriggerable monostable multivibrator $\left(U_{1}\right)$ produces a debounced signal once a test is initiated via switch $S_{1}$.

The Schmitt input buffer $\left(U_{2}\right)$ and its associated circuitry are used to reduce the duration of the pulse to $20 \mathrm{~ns}$. The Schmitt input has adequate hysteresis to generate a jitter-free output. The variable resistor $R_{3}$ is used to change the transition rate of the input signal, which means the output pulse duration can be altered by varying $\mathrm{R}_{3}$, from $10 \mathrm{~ns}$ to $50 \mathrm{~ns}$.

2.4 The Switch Cell Figure 4 shows the schematic diagram of the switch cell, the transformer and the $R_{\text {load }}$ $(40 \Omega)$. The switch cell utilizes a gate driver to control a HV power MOSFET with a short duration pulse. The MOSFET

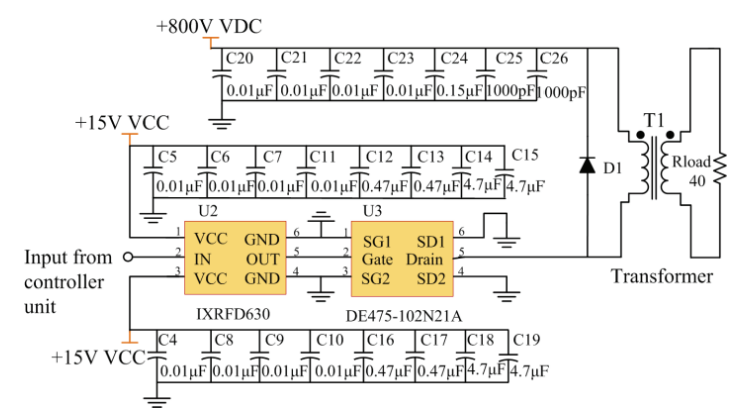

Fig. 4. The schematic diagram of the gate drive and $\mathrm{HV}$ MOSFET circuit board

is powered by a $+700 \mathrm{~V} V_{d c}$ supply in this case. The source is connected to the circuit ground and the drain is connected to the primary winding of the transformer $\left(T_{1}\right)$.

An IXYS nMOS DE475-102N21A (U3) rated at $1000 \mathrm{~V}$, $21 \mathrm{~A}$ and $30 \mathrm{MHz}$ is selected because of its nanosecond switching speed (typically $5 \mathrm{~ns}$ ), low turn on resistance $R_{g}$ $(0.41 \Omega)$, and low stray inductance at the drain and the source terminals, $L_{G}(1 \mathrm{nH})$ and $L_{S}(0.5 \mathrm{nH})$.

An ultra-fast recovery diode $D_{1}$ (RHRG30120) is in parallel with the primary winding so as to freewheel the magnetizing and leakage current when the switch turns off. The anode of the diode should also be placed as close as possible to the drain of the MOSFET, so as to reduce the overshoot voltage due to commutation current flowing through the stray inductance.

The performance of the MOSFET switch in the system is significantly affected by the gate drive circuitry, especially when it comes to achieving the nanosecond rise and fall times. A CMOS high speed high current gate driver IXYS IXRFD630 $\left(U_{2}\right)$ is used because it can source and sink sufficient peak current, $30 \mathrm{~A}$, to fully charge the MOSFET $C_{g s}$ within $4 \mathrm{~ns}$. Also, the minimum pulse width $(8 \mathrm{~ns})$, generated by the gate driver, is shorter than the design requirement $(20 \mathrm{~ns})$. The IXRFD630 driver is a surface-mount device and incorporates patented RF layout techniques and a similar low inductance design to the MOSFET package.

The gate driver is powered by a $+15 \mathrm{~V}$ supply, $V_{c c}$. It is bypassed via a group of surface mount capacitors $\left(C_{4}\right.$ through $C_{19}$ ), which are symmetrically located on the two sides of $U_{2}$. These surface mount capacitors can provide the $30 \mathrm{~A}$ gate drive current in 2-6ns and are low inductance, low equivalent series resistance and high pulse current service capacitors. The capacitors avoid sags or ringing on the gate signal. Three different capacitance values are selected, $0.01 \mu \mathrm{F}$, $0.47 \mu \mathrm{F}$ and $4.7 \mu \mathrm{F}$.

2.5 Transformer Design The transformer uses nanoscale crystalline toroidal core (FINEMET F1AH0898) with o.d. $104 \mathrm{~mm}$ i.d. $76 \mathrm{~mm}$ and height $25 \mathrm{~mm}$. This material is selected because of its superior magnetic properties in the application of nano-second pulse generation, including high saturation magnetic flux density $\left(B_{s}\right)$ of $1.23 \mathrm{~T}$, high permeability and low core loss. One layer of PVC insulation tape is wrapped around the primary and secondary foils fabricated from copper strip of thickness $0.4 \mathrm{~mm}$ and width $22 \mathrm{~mm}$. The following relations are used to estimate the magnetizing inductance $\left(L_{m}\right)$, the leakage inductance $\left(L_{\text {leakage }}\right)$, the interwinding capacitance for the single layer winding $\left(C_{d s}\right)$ and 
Table 1. Specification of Parameter Values Used in Simulation

\begin{tabular}{|l|l|l|}
\hline Parameter & Name & Value \\
\hline$V_{d c}$ & High voltage supply & $700 \mathrm{~V}$ \\
\hline$R_{\text {load }}$ & Load resistance & $40 \Omega$ \\
\hline$L_{\text {leakage }}$ & Leakage inductance & $30 \mathrm{nH}$ \\
\hline$L_{\text {trace }}$ & Trace inductance & $100 \mathrm{nH}$ \\
\hline$R_{\text {winding }}$ & Winding Resistance & $0.8 \Omega$ \\
\hline$L_{m}$ & Magnetizing inductance & $0.8 \mu \mathrm{H}$ \\
\hline$C_{s}$ & Stray capacitance & $20 \mathrm{pF}$ \\
\hline$C_{d}$ & Inter winding capacitance & $25 \mathrm{pF}$ \\
\hline
\end{tabular}

the stray capacitance $\left(C_{s}\right)$ between the foil winding and the core. The calculated values of $C_{d}, C_{s}, L_{\text {leakage }}$ and $L_{m}$ are given in Table 1.

The magnetizing inductance is estimated using ${ }^{(19)}$

$$
L_{m}=\frac{N^{2} t \mu_{r} \mu_{0}}{2 \pi} \ln \frac{b}{a}
$$

Where $\mu_{r}$ is the relative permeability of the magnetic material, $\mu_{0}$ is the permeability of free space, $b$ is the outer diameter of the toroidal core (m), $a$ is the inner diameter of the toroidal core $(\mathrm{m}), t$ is the thickness of the toroidal core $(\mathrm{m})$ and $N$ is the number of the primary turns.

The leakage inductance is estimated using ${ }^{(20)}$

$$
L_{\text {leakage }}=\frac{2 \pi \operatorname{MLTN}^{2}\left(c+\frac{d_{1}+d_{2}}{3}\right)}{\mathrm{L}_{\mathrm{c}}} \times 10^{-8} H \ldots
$$

Where a is the height of the winding in meter, $d_{1}$ is the thickness of the secondary winding, $d_{2}$ is the thickness of primary winding, $c$ is the distance between the primary and secondary windings, $L_{C}$ is the thickness of the core and MLT is the mean length of a turn.

The interwinding capacitance is ${ }^{(21)}$

$$
C_{d}=\frac{\varepsilon \varepsilon_{0} S}{2 h_{1}+h_{2}} F \ldots \ldots \ldots \ldots \ldots \ldots \ldots \ldots \ldots \ldots \ldots \ldots
$$

Where $h_{1}$, and $h_{2}$ are the insulation thickness of PVC and air respectively, $\varepsilon$ and $\varepsilon_{0}$ are the relative and free space permeability respectively, $S$ is the surface area of the edges of the secondary foil $\left(\mathrm{m}^{2}\right)$.

The stray capacitance is ${ }^{(21)}$

$$
C_{s}=\frac{\varepsilon \varepsilon_{0} S}{h_{1}+h_{2}} F \text {. }
$$

Where $S$ is the surface area of the foil adjacent to the core.

The modular nanosecond pulse generation system with two switch cells is represented using the LTspice software, as shown in Fig. 5. Because the single layer secondary is wound near a one-layer primary and the distance between them is small, the transformer is modeled by a lumped circuit ${ }^{(22)}$. It includes the winding resistance $\left(R_{\text {winding }}\right)$, the primary inductances $L_{p}$, the secondary inductance $L_{s}$, the magnetizing inductance $L_{m}$, the leakage inductance $\left(L_{\text {leakage }}\right)$ and the interwinding capacitance $C_{d} . \quad C_{d}$ and $C_{s}$ models the interwinding capacitance of $P$ and $S$ as well as stray capacitance. The winding resistance $R_{\text {winding }}$ is measured at DC in the laboratory. $L_{\text {load }}$ accounts for the parasitic inductance of $R_{\text {load }}$. Table 1 specifies these circuit elements. The lumped circuit model simplifies the analysis of the circuit.

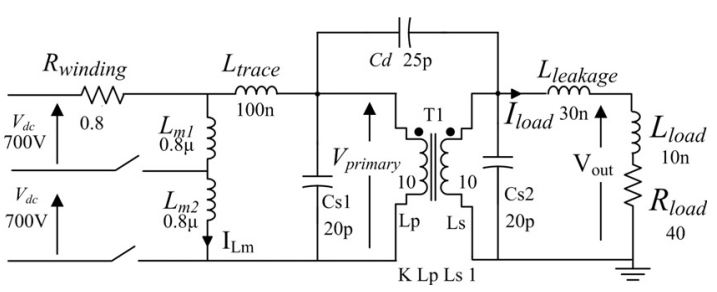

(a) Series coupled two switch cells.

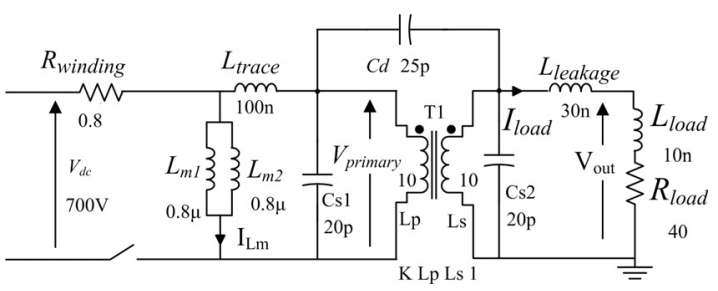

(b) Parallel coupled two switch cells.

Fig. 5. The transformer model of the system with two switch cells

In the series-coupled configuration, $L_{m 1}$ and $L_{m 2}$ are connected in series in the equivalent circuit so that $2 V_{d c}$ is magnetically coupled to the secondary. However, $L_{m 1}$ and $L_{m 2}$ are parallel connected in parallel-coupled configuration, which means only one $V_{d c}$ is coupled to the secondary. This configuration helps reduce leakage inductance and increase drive current capability, compared with the method of connecting switches in parallel and increasing the number of primary turns.

\section{Experimental Results}

The following experiments demonstrate that the nanosecond pulse generation system is scalable in voltage and current. Coupling switch cells in parallel can increase the peak current capability of the system for a given MOSFET current rating. Coupling switch cells in series amplifies the input supply by the number of switch cells.

Each configuration is examined under two load conditions: the transformer is unloaded (open circuit) and loaded with a $40 \Omega$ resistor. The same experimental parameters are used for each condition: $V_{d c}=700 \mathrm{~V}$ and a 20 ns gate signal is fed into the gate driver.

The prototype of the single switch cell is shown in Fig. 6. The DC voltage supply $(700 \mathrm{~V})$ is employed to power the switch cell; the transformer is loaded with a $40 \Omega$ resistor. It should be noted that the transformer core is reset by the DC reset circuit before each test is performed.

3.1 Two Switch Cells Coupled in Parallel Figure 7 shows the prototype of the nanosecond pulse generation system with two switch cells, magnetically coupled in parallel with only one high-voltage DC supply, $V_{d c}(700 \mathrm{~V})$ employed to power both switch cells. The secondary winding, $S$, is located between two primary windings $P_{1}$ and $P_{2}$ in order to improve the magnetic coupling and reduce leakage inductance. This method is superior to the method of connecting switches in parallel to increase the number of primary transformer turns. This is because this configuration is that the peak current capability of the system is increased because each primary winding shares half the load current. Also, the equivalent leakage inductance seen by the load $(40 \Omega)$ is reduced by half, but the distributed capacitance accounting for 


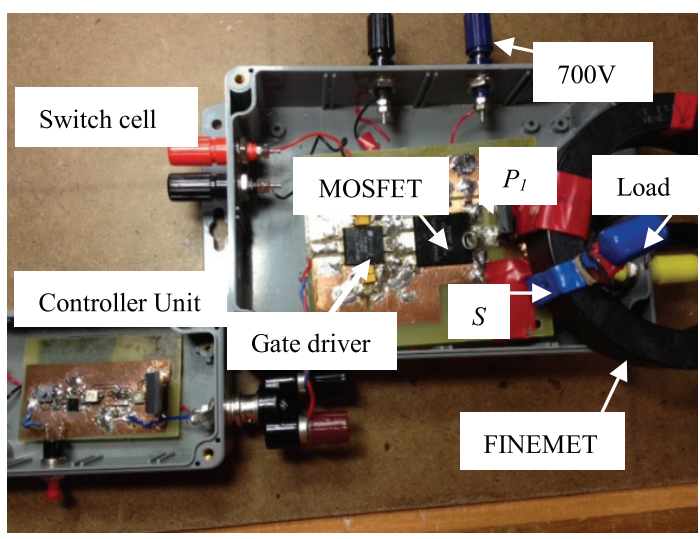

Fig. 6. The prototype of the nanosecond pulse generation system with a single switch cell

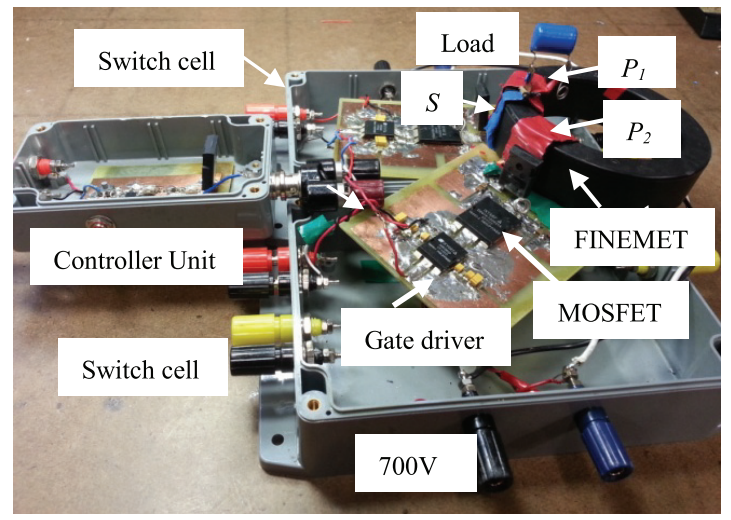

Fig. 7. The prototype of two switch cells coupled in parallel

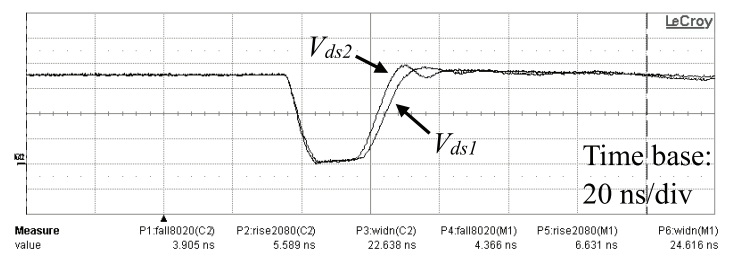

Fig. 8. The measured waveforms under the loaded condition (40 $\Omega$ resistor) showing $V_{d s 1}(\mathrm{M} 1,200 \mathrm{~V} /$ div) with $t_{\text {rise }}=6.6 \mathrm{~ns}, t_{\text {fall }}=4.4 \mathrm{~ns}$, and $V_{d s 2}(\mathrm{C} 2,200 \mathrm{~V} / \mathrm{div})$ with $t_{\text {rise }}=5.6 \mathrm{~ns}$ and $t_{\text {fall }}=3.9 \mathrm{~ns}$

the inter coil capacitance of two primary windings increases.

The loaded condition with a $40 \Omega$ resistor is examined first. Figure 8 shows both MOSFETs in the switch cells are triggered simultaneously. At turn on, the two voltage trajectories $V_{d s 1}$ and $V_{d s 2}$ are synchronized and well matched. When the switches are turned off, the turn-off voltage transients are no longer synchronized and are mis-matched. As a result, the pulse width of $V_{d s 1}$ is stretched to $24.6 \mathrm{~ns}$, although duration of the gate signal is $20 \mathrm{~ns}$. The second primary winding affects the distributed capacitance between the windings, leading to the mismatch between $V_{d s 1}$ and $V_{d s 2}$.

Figures 9(a) and 9(b) show the waveforms of $I_{\text {primary } 1}$ and $I_{\text {primary2 }}$, as well as $V_{d s 1}$ and $V_{d s 2}$. The two primary windings share equal current with maximum amplitude of $28 \mathrm{~A}$. They are composed of $I_{m}$ and a half of $I_{l o a d}$, indicating $I_{m}$ is $\sim 20 \mathrm{~A}$.

The $I_{\text {load }}$ and $V_{\text {out }}$ are illustrated in Fig. 9(c). $V_{\text {out }}$ experiences a slight overshoot and reaches $650 \mathrm{~V}$ with a width of $23.4 \mathrm{~ns}$ and a small overshoot. Both the fall time $(5.6 \mathrm{~ns})$ and

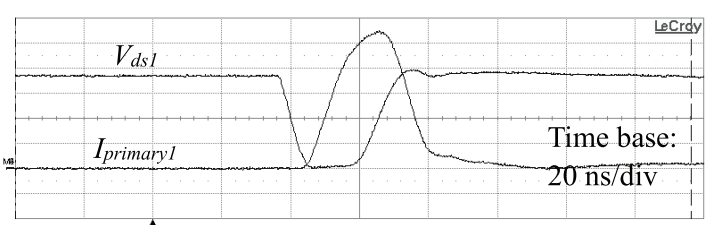

(a) $V_{d s 2}(\mathrm{M} 4,200 \mathrm{~V} / \mathrm{div})$ and $I_{\text {primary2 }}(\mathrm{M} 3,5 \mathrm{~A} / \mathrm{div})$

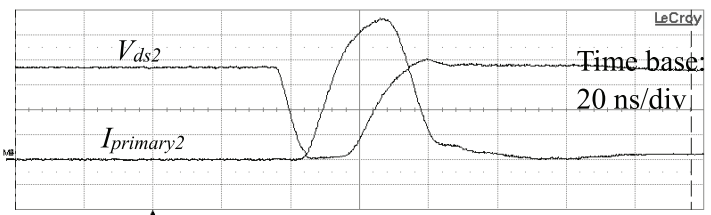

(b) $V_{d s 1}(\mathrm{M} 4,200 \mathrm{~V} / \mathrm{div})$ and $I_{\text {primary } 1}(\mathrm{M} 2,5 \mathrm{~A} / \mathrm{div})$

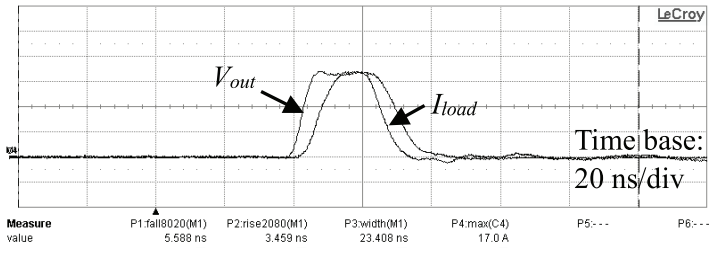

(c) $V_{\text {out }}(\mathrm{M} 1,200 \mathrm{~V} / \mathrm{div})$ and $I_{\text {load }}(\mathrm{C} 4,5 \mathrm{~A} / \mathrm{div})$

Fig. 9. Experimental results of the two switch cells coupled in parallel under the loaded condition ( $40 \Omega$ resistor)

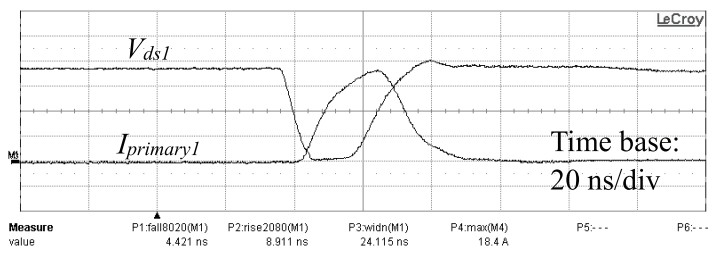

(a) $V_{d s 1}(\mathrm{M} 1,200 \mathrm{~V} / \mathrm{div})$ with $t_{\text {rise }}=8.9 \mathrm{~ns}$ and $t_{\text {fall }}=4.4 \mathrm{~ns}$ and $I_{\text {primary } 1}$ (M3, 5 A/div)

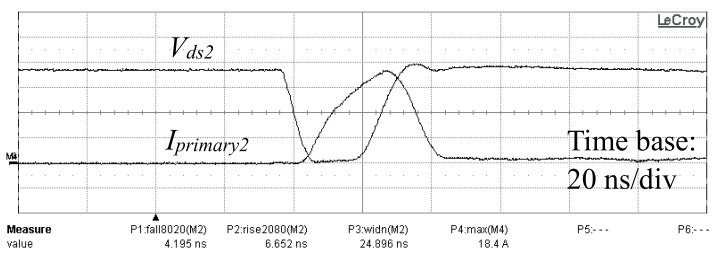

(b) $V_{d s 2}(\mathrm{M} 2,200 \mathrm{~V} / \mathrm{div})$ and $I_{\text {primary2 }}(\mathrm{M} 4,5 \mathrm{~A} / \mathrm{div})$

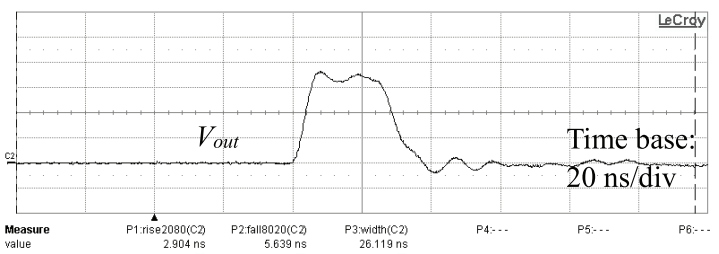

(c) $V_{\text {out }}(\mathrm{C} 2,200 \mathrm{~V} / \mathrm{div})$

Fig. 10. Experimental results of the two switch cells coupled in parallel under no load condition

rise time $(3.5 \mathrm{~ns})$ are smaller than $6 \mathrm{~ns}$. The shape of $I_{\text {load }}$ suffers from distortion; that is, longer rise time and fall time in comparison with $V_{\text {out }}$. Part of the reason for this is the limited bandwidth $(100 \mathrm{MHz})$ of the current probe. The peak load current is $17 \mathrm{~A}$.

Figure 10 shows the experimental results under the no-load condition. The pulse widths of $V_{d s 1}$ and $V_{d s 2}$ are also affected by the distributed capacitance and extended to $24.1 \mathrm{~ns}$ and $24.9 \mathrm{~ns}$, respectively. The rise time of $V_{d s 1}$ and $V_{d s 2}$ are $2 \mathrm{~ns}$ longer than that in the loaded condition because of the 
reduced primary current $(\approx 18 \mathrm{~A})$. A reduced primary current contributes to slower MOSFET turn-off as $C_{d s}$ is charged slowly by the primary current.

Figure $10(\mathrm{c})$ shows $V_{\text {out }}$ with a width of $26.1 \mathrm{~ns}$ has a fall time of $5.6 \mathrm{~ns}$ and a rise time of $2.9 \mathrm{~ns}$, which is shortest transient time in all the experiments, as expected. The peak in $V_{\text {out }}$ is almost $700 \mathrm{~V}$.

The experimental results prove that the two switch cells coupled in parallel can generate a $23.4 \mathrm{~ns}$ voltage pulse, which satisfies the requirement of rise time and fall time. The parallel coupling relieves the current burden on the MOSFET. It increases the peak current capability of the system for a given MOSFET current rating. The increased equivalent distributed capacitance in the parallel configuration is considered as the dominant factor causing the distortion of the output pulse response, including mismatching of $V_{d s 1}$ and $V_{d s 2}$ at turn off and extended pulse width of $V_{\text {out }}$.

3.2 Two Switch Cells Coupled in Series The experimental set up of two switch cells coupled in series is shown in Fig. 11. The same $V_{d c}(700 \mathrm{~V})$ and load resistor $(40 \Omega)$ are employed. Each FINEMET core associated with a switch cell is stacked to inductively add the cell output voltages. Therefore, $V_{\text {out }}$ can be made a multiple of $V_{d c}$ (in this case, 2). However, the leakage inductance is increased due to the increased length of foil in the practical set-up and therefore the equivalent leakage inductance seen by the load resistor is doubled due to series coupling.

Figure 12 shows the drain to source voltage when the system is tested under the loaded condition. $V_{d s 1}$ and $V_{d s 2}$ are synchronized and well matched during both the turn-on and turn-off, unlike the parallel-coupled two switch cell configuration. This means the influence of distributed capacitance is

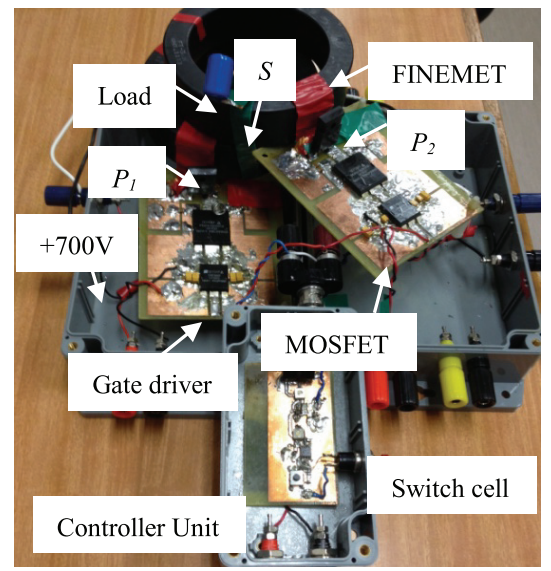

Fig. 11. The prototype of two switch cells coupled in series

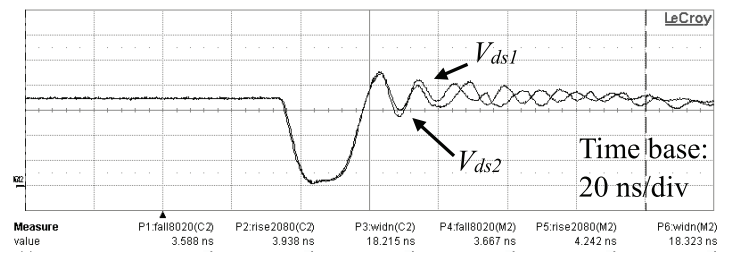

Fig. 12. The measured waveforms under loaded condition showing $V_{d s 1}(C 2,200 \mathrm{~V} /$ div $)$ with $t_{\text {rise }}=3.9 \mathrm{~ns}, t_{\text {fall }}$ $=3.6 \mathrm{~ns}$, width $=18.2 \mathrm{~ns}$, and $V_{d s 2}(\mathrm{M} 2,200 \mathrm{~V} / \mathrm{div})$ with $t_{\text {rise }}=4.2 \mathrm{~ns}, t_{\text {fall }}=3.7 \mathrm{~ns}$, width $=18.2 \mathrm{~ns}$ not as significant as in the parallel configuration. The pulse width is around $18 \mathrm{~ns}$.

Unfortunately, $V_{\text {out }}$ experiences distortion, as shown in Fig. 13(a). It has a rise time of $7.7 \mathrm{~ns}$ and fall time of $6.3 \mathrm{~ns}$, which are longer than that in parallel configuration. The increase in rise time is caused by the doubled equivalent leakage inductance seen by load resistor, which leads to a doubled load current time constant.

The doubling effect of the series coupled configuration is proved by the waveforms of output load voltage $\left(V_{\text {out }}\right)$, primary current, ( $I_{\text {primary } 1}$ and $\left.I_{\text {primary } 2}\right)$, as well as load current $\left(I_{\text {load }}\right)$, shown in Figs. 13(a), (b) (c) and (d). $\hat{V}_{\text {out }}$ reaches 1044 V. $\hat{I}_{\text {load }}$ is approximately $22 \mathrm{~A}$. Also, $\hat{I}_{\text {primary }}(36.2 \mathrm{~A})$ and $\hat{I}_{\text {primary } 2}(37.6 \mathrm{~A})$ are close to expectation $(40 \mathrm{~A})$.

Figure 14 shows the measured waveforms when the load is disconnected. $V_{\text {out }}$ reaches $1200 \mathrm{~V}$ in $3.3 \mathrm{~ns}$ at turn-on and $0 \mathrm{~V}$ in $5.4 \mathrm{~ns}$ at turn-off. The MOSFET is turned on and off in $5.3 \mathrm{~ns}$ and $5.2 \mathrm{~ns}$, respectively. The magnetizing current, $I_{m 1}$, which equals to $I_{\text {primary }}$, is still $19 \mathrm{~A}$. It is demonstrated that, when the transformer is disconnected from the load, the series coupling configuration can deliver a narrow pulse $(18.2 \mathrm{~ns})$ with fast rise time $(<6 \mathrm{~ns})$ and fall time $(<$ $6 \mathrm{~ns})$, which meets the design criteria.

When the load is connected, the series coupling can still generate a voltage pulse as requested but only when the $R_{\text {load }}$ is increased high enough to maintain an appropriate time constant with the increased leakage inductance. This is shown in Fig. 15. A $1100 \mathrm{~V} / 18 \mathrm{~ns}$ pulse with rise time of $4.3 \mathrm{~ns}$ fall time of $4.1 \mathrm{~ns}$ is produced when $R_{\text {load }}=120 \Omega$. This confirms that the increased leakage inductance is a major factor affecting

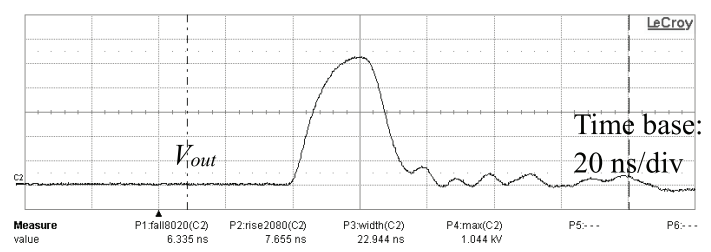
(a) $V_{\text {out }}(\mathrm{C} 2,200 \mathrm{~V} / \mathrm{div})$

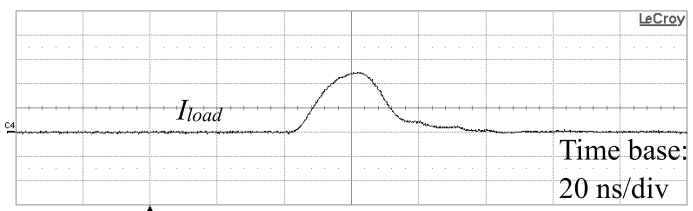

(b) $I_{\text {load }}(\mathrm{C} 4,10 \mathrm{~A} / \mathrm{div})$

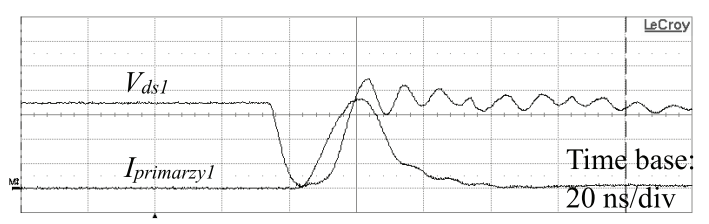

(c) $V_{d s 1}(\mathrm{M} 1,200 \mathrm{~V} / \mathrm{div})$ and $I_{\text {primary } 1}(\mathrm{C} 4,10 \mathrm{~A} / \mathrm{div})$

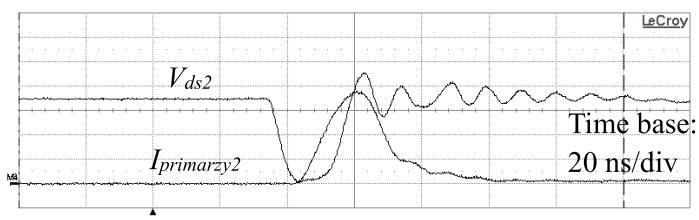

(d) $V_{d s 2}(\mathrm{M} 4,200 \mathrm{~V} / \mathrm{div})$ and $I_{\text {primary2 } 2}(\mathrm{M} 3,10 \mathrm{~A} / \mathrm{div})$

Fig. 13. Experimental results of the two switch cells coupled in series in loaded condition ( $40 \Omega$ resistor) 


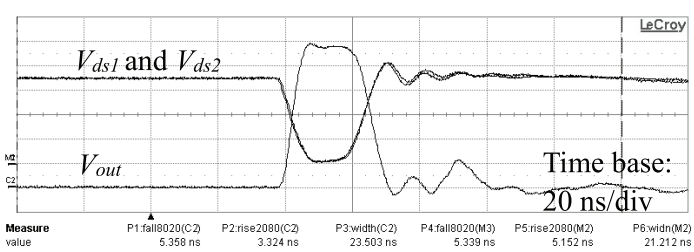

(a) $V_{d s}(\mathrm{M} 1$ and $\mathrm{M} 2,200 \mathrm{~V} / \mathrm{div})$ and $V_{\text {out }}(\mathrm{C} 2,200 \mathrm{~V} / \mathrm{div})$

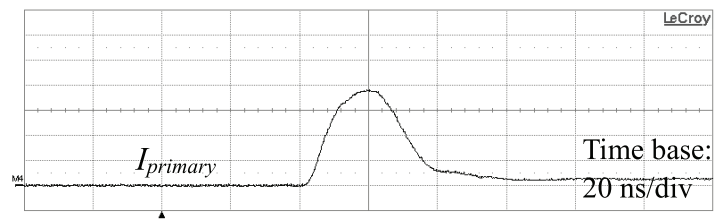

(b) $I_{\text {primary }}(\mathrm{M} 4,5 \mathrm{~A} / \mathrm{div})$

Fig. 14. The measured waveforms in no load condition

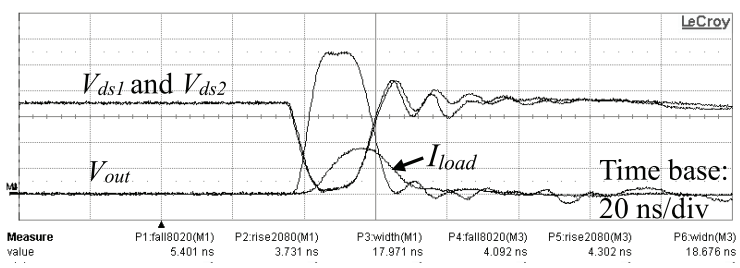

Fig. 15. The demonstration of generating $V_{\text {out }}$, which has improved rise time and fall time with $R=120 \Omega$. $V_{\text {out }}$ (M3, $200 \mathrm{~V} / \mathrm{div}), V_{d s}(\mathrm{M} 1$ and $\mathrm{M} 2,200 \mathrm{~V} / \mathrm{div})$ and $I_{\text {load }}$ (M4, $5 \mathrm{~A} / \mathrm{div})$ are displayed

Table 2. Comparison of $\mathrm{V}_{\mathrm{ds}}$ and $\mathrm{V}_{\text {out }}$ with parallel coupling

\begin{tabular}{|l|c|c|c|c|c|c|}
\hline \multirow{2}{*}{ Parameter } & \multicolumn{3}{|c|}{ Waveforms (without load) } & \multicolumn{3}{|c|}{ Waveforms (with load) } \\
\cline { 2 - 7 } & $\begin{array}{c}V_{d s 1} \\
(\mathrm{~ns})\end{array}$ & $\begin{array}{c}V_{d s 2} \\
(\mathrm{~ns})\end{array}$ & $\begin{array}{c}V_{\text {out }} \\
(\mathrm{ns})\end{array}$ & $\begin{array}{c}V_{d s 1} \\
(\mathrm{~ns})\end{array}$ & $\begin{array}{c}V_{d s 2} \\
(\mathrm{~ns})\end{array}$ & $\begin{array}{c}V_{\text {out }} \\
(\mathrm{ns})\end{array}$ \\
\hline Rise time & 6.7 & 8.9 & 2.9 & 6.6 & 5.6 & 3.5 \\
\hline Fall time & 4.2 & 4.4 & 5.6 & 4.4 & 3.9 & 5.6 \\
\hline Duration & 24.9 & 24.1 & 26.3 & 24.6 & 22.6 & 23.4 \\
\hline
\end{tabular}

Table 3. Comparison of $V_{d s}$ and $V_{\text {out }}$ with series coupling

\begin{tabular}{|l|c|c|c|c|c|c|}
\hline \multirow{2}{*}{ Parameter } & \multicolumn{3}{|c|}{ Waveforms (without load) } & \multicolumn{3}{|c|}{ Waveforms (with load) } \\
\cline { 2 - 7 } & $\begin{array}{c}V_{d s 1} \\
(\mathrm{~ns})\end{array}$ & $\begin{array}{c}V_{d s 2} \\
(\mathrm{~ns})\end{array}$ & $\begin{array}{c}V_{\text {out }} \\
(\mathrm{ns})\end{array}$ & $\begin{array}{c}V_{d s 1} \\
(\mathrm{~ns})\end{array}$ & $\begin{array}{c}V_{d s 2} \\
(\mathrm{~ns})\end{array}$ & $\begin{array}{c}V_{\text {out }} \\
(\mathrm{ns})\end{array}$ \\
\hline Rise time & 5.2 & 5.2 & 3.3 & 3.9 & 4.2 & 7.7 \\
\hline Fall time & 5.3 & 5.3 & 5.4 & 3.6 & 3.7 & 6.3 \\
\hline Duration & 21.2 & 21.2 & 23.5 & 18.2 & 18.2 & 22.9 \\
\hline
\end{tabular}

the shape of $V_{\text {out }}$ and $I_{\text {load }}$.

3.3 Discussion Table 2 and Table 3 compares the waveforms of drain to source voltages $\left(V_{d s 1}\right.$ and $\left.V_{d s 2}\right)$ and output waveform $\left(V_{\text {out }}\right)$ in terms of rise time, fall time and the duration measured in parallel and series coupled configurations.

It is clear that fall time of $V_{d s}$, ranging from $3.6 \mathrm{~ns}$ to $5.6 \mathrm{~ns}$, has small variation. This means it is the gate current generated by the gate driver that determines the switch on time of the MOSFET, rather than the load condition and the configuration of the system. On the contrary, the rise time of $V_{d s}$ is strongly related to the magnitude of $I_{\text {primary }}$, which charges the $C_{g d}$ and $C_{d s}$ capacitance of the MOSFET to turn off the switch. Since it always decreases when load is removed, the rise time of $V_{d s}$ is always longer than that in the loaded condition in each configuration.

The load time constant, which is dominated by the ratio of equivalent leakage inductance and load resistance (L/R), determines the rise time of $V_{\text {out }}$. Due to the influence of the increased equivalent leakage inductance in series-coupled two switch cell configuration, the rise time $(7.7 \mathrm{~ns})$ of $V_{\text {out }}$ is more than doubled, compared with the turn-on time of MOSFET (3.7 ns). However, the fall time (6.3 ns) is slightly longer than switch off time ( $4.2 \mathrm{~ns})$ because the increased peak load current charges the $\mathrm{C}_{\mathrm{gd}}$ and $\mathrm{C}_{\mathrm{ds}}$ capacitance of the MOSFET to turn off the MOSFET, which in turn affects the fall time of $\mathrm{V}_{\text {out }}$.

$V_{\text {out }}$ in the parallel-coupled switch cell configuration has shorter rise time $(3.5 \mathrm{~ns})$. It is close to the switch-on time of MOSFET (3.9 ns) as reduced equivalent leakage inductance shortens the rise time; however, the extended duration of $V_{\text {out }}$ and $V_{d s}$ is a result of increased distributed capacitance caused by the parallel coupling.

The peak voltage for the single switch cell is $\sim 800 \mathrm{~V}$ because exist of voltage overshoot and the maximum voltage rating of the DE475-102N21A MOFET is $1000 \mathrm{~V}$. The scramjet application will require voltage of tens of $\mathrm{kV}$. Therefore, a multiple number of switch cells are required to scale the system up to $10 \mathrm{kV}$ using series coupling. The equivalent load resistance of the system, which is a contributor to the voltage rise time in the scramjet application, is, as yet, unknown. If the load resistance is large, it is possible to deliver output pulse with nanosecond rise time and fall time, even with the expected increase in leakage inductance. If the load resistance is small, the rise time and fall time will be increased and much attention during the design phase will be required to reduce as far as possible the leakage inductance. Nonetheless, the combination of series and parallel coupling may provide a sufficiently fast rise time. More research investigating the equivalent load of the ignition system is required to better predict the load and optimize the system size and design.

The experimental results show that the parallel coupling configuration can be used to reduce the time constant inferred by the rising edge of $V_{\text {out }}$. The series coupling configuration increases the time constant because of increased leakage inductance. Reducing the leakage inductance and distributed capacitance plays a key role in delivering pulses with fast rise and fall times, and demonstrates that when using series coupling it may well be a requirement to also parallel-couple cells to limit the consequent increase in equivalent leakage inductance.

\section{Conclusion}

A MOSFET-based nanosecond pulse generation system utilizing an inductive voltage adder is proposed, developed and tested. It satisfies the design criteria successfully.

Employing the inductive voltage adder topology, the switch cell can be coupled in series or in parallel to form systems with expanded power capability.

The series-coupled two cell configuration has the feature of amplifying the input supply by the number of switch cells. The increased leakage inductance is responsible for the increased load time constant, which in turn lengthens the rise 
time and fall time of the output pulse.

The parallel-coupled two switch cell configuration has the advantage of increasing the peak current capability of the system for a given MOSFET current rating. The increased equivalent distributed capacitance leads to the mismatch of the drain-to-source voltages at turn-off and distortion of the output pulse. However, the load time constant is decreased.

\section{References}

( 1 ) S.O. Macheret, M.N. Shneider, R.C. Murray, and R.B. Miles: "Ionization in strong electric fields and dynamics of nanosecond-pulse plasmas", Physics of Plasmas, Vol.13, pp.23502-23502 (2006)

( 2 ) E. Mintusov, M. Nishihara, N. Jiang, I. Choi, M. Uddi, A. Dutta, ed: "Nanosecond Pulse Burst Ignition of Ethylene and Acetylene by Uniform Low-Temperature Plasmas", in 39th AIAA Plasmadynamics and Lasers Conference (2008)

( 3 ) I.V. Adamovich, W.R. Lempert, J.W. Rich, Y.G. Utkin, and M. Nishihara: "Repetitively pulsed nonequilibrium plasmas for magnetohydrodynamic flow control and plasma-assisted combustion", Journal of Propulsion and Power, Vol.24, pp.1198-1215 (2008)

( 4 ) N.L. Aleksandrov, S.V. Kindysheva, I.N. Kosarev, S.M. Starikovskaia, and A.Y. Starikovskii: "Mechanism of ignition by non-equilibrium plasma", Proceedings of the Combustion Institute, Vol.32, pp.205-212 (2009)

( 5 ) R. McLeary and W.E.K. Gibbs: "CW CO2 at atmospheric Pressure", Quantum Electronics, IEEE Journal of, Vol.9, pp.828-833 (1973)

( 6 ) N. Basov, I. Babaev, V. Danilychev, M. Mikhailov, V. Orlov, V. Savelev, ed: "Closed cycle CW CO2 laser employing an electron beam ionizer", Soviet Journal of Quantum Electronics, Vol.6, pp.772-781 (1979)

( 7 ) A. Kovalev, E. Murtov, A. Ozerenkeo, A. Rakhimov, and N. Suetin: "Structure of a beam-driven RF discharge in gas flow", Fizika Plazmy, Vol.11, pp.882-888 (1985)

( 8 ) W. Witteman and V.N. Ochkin: Gas lasers: recent developments and future prospects, Vol.10, Kluwer Academic Pub (1996)

( 9 ) N. Generalov, V. Zimakov, V. Kosynkin, Y. P. Raizer, and D. Roitenburg: "Method for significantly increasing the stability limit of the discharge in fast-flow large-volume lasers", Sov. Tech. Phys. Lett. (Engl. Transl.); (United States), Vol.1 (1975)

(10) N. Generalov, V. Zimakov, V. Kosynkin, Y. P. Raizer, and D. Roitenburg: "Method for significantly increasing the stability limit of the discharge in fast-flow large-volume lasers", Sov. Tech. Phys. Lett. (Engl. Transl.); (United States), Vol.1 (1975)

(11) A. Dutta, I. Choi, M. Uddi, E. Mintusov, A. Erofeev, Z. Yin, et al.: "Cavity Flow Ignition and Flameholding in Ethylene-Air by a Repetitively Pulsed Nanosecond Discharge", AIAA Pap, Vol.2009, p.821 (2009)

(12) E. Mintusov, A. Serdyuchenko, I. Choi, W. Lempert, and I. Adamovich: "Mechanism of plasma assisted oxidation and ignition of ethylene-air flows by a repetitively pulsed nanosecond discharge", Proceedings of the Combustion Institute, Vol.32, pp.3181-3188 (2009)

(13) J. Mankowski and M. Kristiansen: "A review of short pulse generator technology", Plasma Science, IEEE Transactions on, Vol.28, pp.102-108 (2000)

(14) K. Yatsui, K. Shimiya, K. Masugata, M. Shigeta, and K. Shibata: "Characteristics of pulsed power generator by versatile inductive voltage adder", Laser and Particle Beams, 23.04, 573-581 (2005)

(15) D. Bortis, J. Biela, and J.W. Kolar: "Transient behavior of solid-state modulators with matrix transformers", Plasma Science, IEEE Transactions on, Vol.38, No.10, pp.2785-2792 (2010)

(16) Z. Ghasemi, S. Macgregor, J. Anderson, and Y. Lamont: "Development of an integrated solid-state generator for light inactivation of food-related pathogenic bacteria", Measurement Science and Technology, Vol.14, No.6, p.N26 (2003)

(17) B. Hickman and E. Cook: "Evaluation of MOSFETs and IGBTs for pulsed power applications", in Pulsed Power Plasma Science. PPPS-2001. Digest of
Technical Papers, Vol.2. IEEE, pp.1047-1050 (2001)

(18) F. Wakeman and B. Green: "Improved semiconductor switches, for pulse power applications", in Conference Record of the 1998 Twenty-Third International Power Modulator Symposium, IEEE, pp.135-138 (1998)

(19) H.A. Mangalvedekar, A.S. Paithankar, D.P. Chakravarthy, K.P. Dixit, and D.N. Barve: "Development of Solid State Pulse Power Modulator Using Toroidal Amorphous Core", IEEE Trans. on Dielectrics and Electrical Insulation, Vol.16, pp.1006-1010 (2009)

(20) A. Naderian-Jahromi, J. Faiz, and H. Mohseni: "Calculation of distribution transformer leakage reactance using energy technique", in Australasian Universities Power Engineering Conference, AUPEC (2002)

(21) H. Taskar, M. Dorlikar, M. Patil, H. Mangalvedekar, and D. Chakravarthy: "Numerical validation of amorphous core pulse transformer", in Power Modulator and High Voltage Conference (IPMHVC), 2010 IEEE International, pp. 271-273 (2010)

(22) M. Akemoto, S. Gold, A. Krasnykh, and R. Koontz: "Pulse transformer R\&D for NLC klystron pulse modulator", in Pulsed Power Conference. Digest of Technical Papers. 11th IEEE International, pp.724-729 (1997)

Peng Gao (Non-member) received her B.E. in 2010 from the Univer-

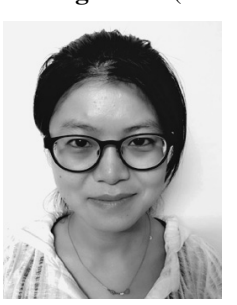
sity of Canterbury in New Zealand. She is currently studying her M.E. degree in the School of Electrical Engineering and Telecommunications at the University of New South Wales. Her research interests include modular MOSFET pulsed-power systems and signal processing.

Sean O'Byrne (Non-member) works at the University of New South

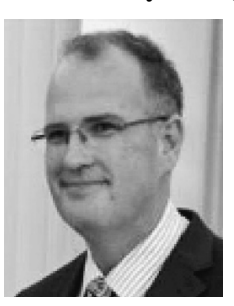
Wales, Canberra, in the application of laser-based diagnostic techniques to high-speed flows and plasmas. He graduated with a Ph.D. in Physics from the Australian National University in 2002 and worked at NASA Langley Research Center on laser-based measurements of supersonic combustion before continuing to work on hypersonic-related problems at the University of New South Wales. His current research is focused upon measurements of temperature and flow speed in rarefied hypersonic flows applicable to spacecraft re-entry, and the application of plasmas to supersonic ignition.

John E. Fletcher (Non-member) received the B.Eng. (with first class

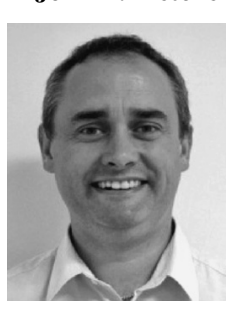
honors) and Ph.D. degrees in electrical and electronic engineering from Heriot-Watt University, Edinburgh, U.K., in 1991 and 1995, respectively. Until 2007, he was a Lecturer at Heriot-Watt University. From 2007 to 2010 , he was a Senior Lecturer with the University of Strathclyde, Glasgow, U.K. He is currently a Professor with the University of New South Wales, Sydney, Australia. He manages research projects, including distributed and renewable integration, silicon carbide electronics, pulsed-power applications of power electronics, and the design and control of electrical machines. His research interests include power electronics, pulsed-power applications of power electronics, and the design and control of electrical machines. Prof. Fletcher is a Charted Engineer in the U.K. and a Fellow of the Institution of Engineering and Technology. 